\title{
An E-Learning Platform for Departmental Use
}

\author{
Grigoris Tziallas, Athanasios Kontogeorgos, Christos Papanastasiou \\ Department of Electronic Engineering, Technological Educational Institute of Sterea Hellas, Lamia, Greece \\ Email: gt@teilam.gr
}

Received 5 April 2016; accepted 14 June 2016; published 17 June 2016

Copyright (C) 2016 by authors and Scientific Research Publishing Inc.

This work is licensed under the Creative Commons Attribution International License (CC BY). http://creativecommons.org/licenses/by/4.0/

(c) (i) Open Access

\section{Abstract}

The paper describes the implementation of an e-learning platform to be used by the Department of Electronics of the Technological Educational Institute of Lamia. The e-learning platform is based on Claroline, which is an existing open source implementation of a collaborative learning environment. Claroline has been enhanced and linked with the departmental database and the existing institutional web site. The e-learning platform uses information from the departmental database in order to automatically enroll students into courses, and assign teachers as course tutors. It enables students to have access to information such as degrees from past exams, courses passed and their current status. It also enables teachers to have access to statistical data regarding their students' performance. The paper describes in detail the functionality, the architecture and the implementation of the e-learning platform.

\section{Keywords}

\section{E-Learning, Course Management System}

\section{Introduction}

A Course Management System (CMS) is an Internet-based software that manages student enrollment, tracks student performance, and also creates and distributes course content (Ullman \& Rabinowitz, 2004; Morgan, 2003). The CMS enables teachers to extend the classroom beyond its traditional boundaries.

Although there exists a variety of systems on the market, every CMS contains some implementation of the following functions:

- Authoring/Publishing Tools: These tools allow the instructor to publish files for students to download, allow students to upload files, facilitate the creation and publication of web pages, enable access to audio or video streams and allow the creation of online tests in a variety of formats (e.g., multiple choice, short answer, es- 
say, etc.).

- Communication tools: Every CMS enables instructors and students, both individually and as a group, to communicate online. Communication can be synchronous or asynchronous.

- Class Creation: The CMS supports the creation of classes and the assignment of one or more instructors to a class and the on-line registration of students.

- Interface to Registrar's Database: The CMS might be connected to the database of the institution's registrar and supply automatically data to the CMS.

- Password management: Access for both teachers and students is password protected.

- Track student performance and grades: The CMS offers the ability to capture students' performances on tests and their resulting grades. It also includes the ability to manually enter grades for papers and projects or other tests.

The CMS became widely available in 1997, and its popularity and use have increased dramatically ever since. Some common commercial systems include:

- Blackboard, http://www.blackboard.com

- eCollege, http://www.ecollege.com

- WebCT, https://en.wikipedia.org/wiki/WebCT

These software solutions have been widely marketed to and adopted by colleges and universities.

Some open source CMS include:

- Moodle, http://moodle.org/

- Claroline, http://www.claroline.net/

- Atutor, http://www.atutor.ca/

Claroline has been selected by the Department of Electronics of the Technological Educational Institute of Lamia as the CMS educational tool allowing the professor to create, administer and feed his/her courses through the web. Claroline has already been selected by GUNET (The Greek Universities Net) as the basis for implementing eclass, an e-learning platform already used by our Institution as an educational tool.

Claroline has been enhanced and linked with the departmental database and the existing institutional web site. The resulted e-learning platform uses information from the departmental database in order to automatically enroll students into courses, and assign teachers as course tutors. It also generates statistical information and provides a grading book for teachers. The paper describes in detail the functionality, the architecture and the implementation of the e-learning platform.

The novelty and the significance of this approach rely on the integration of a CMS with the existing registrar's database and the web site of the department. A generic architecture for integrating the CMS is presented that can be used by other Institutions.

\section{Claroline Description}

Claroline is free software distributed under the GNU Public License GPL software working with PHP/MySQL. Claroline was developed at the Université Catholique de Louvain, Belgium, providing instructors with an e-learning platform that is easy to use. The maturity of Claroline can be attributed to having a large user base that has contributed to its development.

Features included within Claroline:

- Instructors can set courses to be publicly accessible or can protect access to individual courses with a username and password.

- Instructors can add students to a course or students can self-register.

- Instructors can use templates to create agendas, announcements, course content, discussion forums, links and the syllabus and course descriptions.

- Instructors can upload video files for use as course resources

- Instructors can create self-assessments. The system automatically scores multiple choice, true/false, and multiple answer type questions and can display instructor-created feedback.

- Instructors can get reports showing the number of times all students in a course as an aggregated group accessed course content.

- Instructors can access context sensitive help and numerous instructor support forums through the development community website. 
- Students must have an external Internet email address. Students can use the Internal email feature to email individuals.

- Synchronous communication: Students and Instructors may access the chat facility for all users.

- Asynchronous communication: Students and instructors may participate into discussion forums.

- Students can upload their own papers to the system for peer review.

Claroline's main strength is ease of use. The interface is very intuitive and it is very simple for instructors and students to use it. Claroline lends itself extremely well to asynchronous e-learning. Announcements, message boards and contact lists encourage collaboration. Claroline's documentation is excellent and provides good insights into what the system can and cannot do.

Claroline is translated in 28 languages and used by hundreds of institutions around the world. Downloading and using Claroline is completely free of charge.

\section{Extentions to Claroline}

In order to cover the needs of our department, Claroline has been extended with the following features, which are not available in Claroline or in the GUNET eclass:

- Claroline is automatically updated with new students registrations by using information from the registrar's database.

- Every new semester students are automatically enrolled into Claroline courses using information from the registrar's database.

- Every new semester instructors are automatically assigned to courses.

- Students, when logging into Claroline are presented with a list of the courses they have to attend the current semester.

- Students have the option to permit the on-line availability of their grades.

- Students may have access to their grades and course material of previous semesters.

- Tutors may track their student's performance and grades. A tutor is restricted to access only grades related to courses that he/she has been assigned as instructor.

- Tutors and students may access various statistical data and charts related to grades, courses, course enrollment, average duration of studies, etc.

\section{The E-Learning Platform}

The e-learning platform under development consists of the adapted Claroline and a set of tools that extend the functionality of Claroline. The tools are:

- The database interface: The database interface is a software tool used for retrieving information from the registrar's database.

- The semester management tool: The semester management tool is used by the administrator in order to handle semesters, backup data from previous semesters, create new courses, enroll students, and assign instructors to courses.

- The grading tool: Instructors use the grading tool in order to assign grades to their students and track their performance.

- The statistics tool: The statistics tool generates statistical data and charts related to students, courses and tutor grades.

The e-learning platform uses the e-learning database in order to store data retrieved from the registrar's database. The e-learning database stores data related to students, courses, student grades, courses, instructors and the assignment of tutors to courses.

The architecture of the e-learning platform is shown in Figure 1.

\subsection{The Database Interface}

The database interface retrieves data from the registrar's database and stores them in the e-learning database. Access to the database interface is restricted to administrators. For security reasons the database interface has read-only access to the registrar's database. A read only ODBC driver is used to retrieve data from a backup of the registrar's database. 


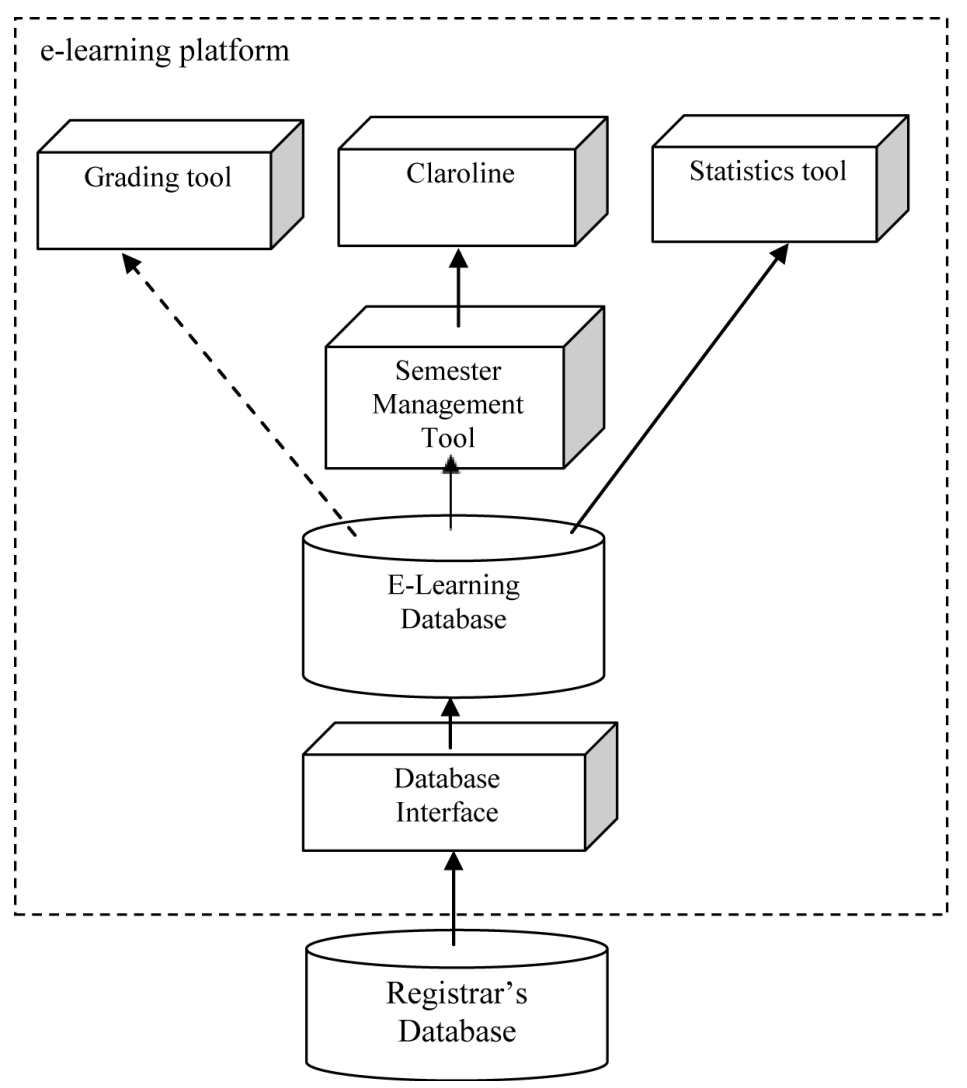

Figure 1. The e-learning platform architecture.

\subsection{The Semester Management Tool}

The semester management tool is used to update Claroline automatically every semester. Access to the semester management tool is restricted to administrators. The semester management tool has the following functionality:

- New semester creation: The administrator may create a new semester. A new Claroline database is created. Student, tutor and course data are copied to the new database. The Claroline database and courses are initialized.

- Update function: The update function uses data from the e-learning database in order to automatically enroll students into courses and assign instructors to courses. Student grades are also transferred to Claroline only for those students that wish to have online access to their grades.

- Course information management: A course management form may be used by the administrator in order to specify various course information such as course content, teaching-training activities, human and physical resources and methods of evaluation. The administrator is responsible for supplying course information in a uniform format for all courses. Instructors may alter, if they wish, course information for the current semester.

\subsection{The Statistics Tool}

The statistics tool allows tutors and students to access statistical data and charts such as:

- Distribution of grades for a specific course and semester (Figure 2).

- Average grades of a semester's courses.

- Average grades of a specific course for all semesters.

- Average duration of studies.

- Various charts related to the number of students enrolled into courses

The statistics tool also enables authorized instructors to access statistical data and charts comparing and tracking tutor performance. 


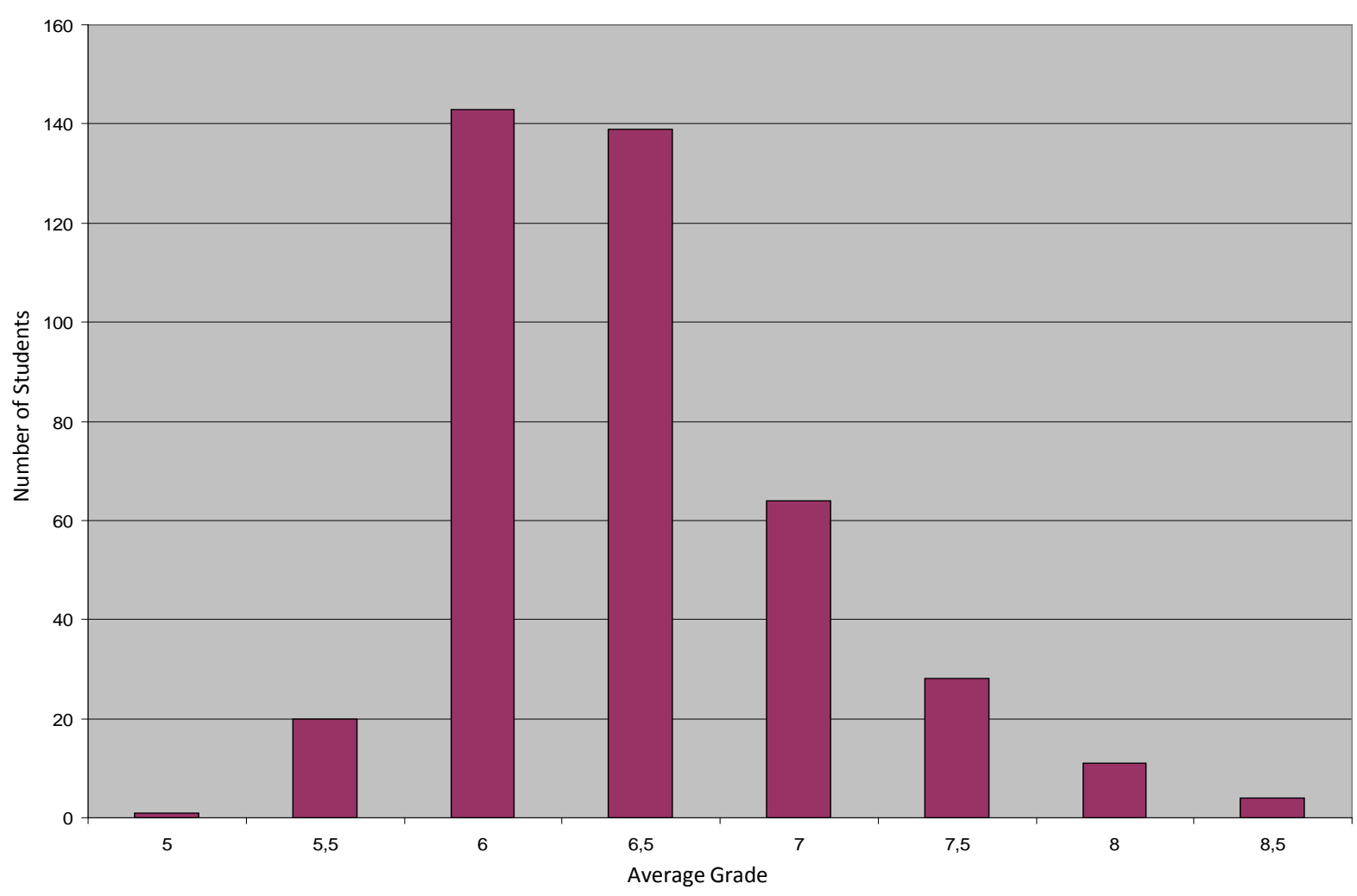

Figure 2. Statistics tool: Grades.

\subsection{The Grading Tool}

Tutors can use the grading tool in order to store and keep track of the grades that they enter manually. The grading tool is an individual off-line application, which is distributed to the tutors that wish to use it. The grading tool uses its own database for storing data and has the following functionality:

- Semester selection: The tutor may define the current semester

- Import students function: The tutor may import a file with the list of students enrolled to a course

- Select examination type: The tutor may define the examination type (e.g. lab, intermediate, first period, or second period examination)

- Enter grades manually: The tutor may select a student by entering the name or id in order to manually enter the grade. While entering a grade for a specific student, the tutor may track the student performance over past exams, assignments and exercises.

- Produce reports and export data: The tutor may produce reports of student grades for a specific course. Reports are stored in MS-Word files and stored on the local database. Tutors may also export data in a format that can be used for automatically importing grades by the registrar's database.

- Check registrar's database grades: An important feature of the grading tool is that it allows tutors to check that their grades have been correctly entered in the registrar's database. A tutor may check at any time that the grades for a specific course and semester match the grades of the registrar's database.

\section{Conclusions}

An e-learning platform has been presented for departmental use. The e-learning platform has been based on Claroline, which is an open source CMS.

The selected CMS has been successfully extended in order to be able to handle semesters, which we consider as an important feature for educational institutes. Central management of course information has also been added as a feature to the e-learning platform. The administrator supplies information for all courses to the e-learning database and, every semester, html pages and information for all courses are automatically generated. 
Course enrollment and assignment of tutors to courses is automated by using information from the registrar's database, thus easing the task of maintaining and keeping up to date the e-learning platform.

The grading tool assists teachers to keep track of their grades and track the performance of their students and the statistics tool supplies tutors and students with valuable data and charts regarding their performance.

The e-learning platform has been evaluated and is currently being used by the Department of Electronics of the Technological Educational Institute of Lamia.

The database interface has been tested for transferring student data to the e-learning system, the semester management tool has successfully created semesters and courses, several teachers are currently using the grading tool and various statistics are available by the e-learning platform for the semesters that the system is in use.

\section{Acknowledgements}

This work and its dissemination efforts have been funded by the Greek Operational Programme for Education and Initial Vocational Training (O.P. Education) under the action: 2.2.2. "Reformation of Undergraduate Studies Programs".

\section{References}

Morgan, G. (2003). Faculty Use of Course Management Systems. EDUCAUSE Center for Applied Research (ECAR). http://www.educause.edu/ecar/

Ullman, C., \& Rabinowitz, M. (2004). Course Management Systems and the Reinvention of Instruction. Technical Horizons in Education. http://thejournal.com/magazine/vault/A5070.cfm 